\title{
The Number of Glutamate Receptors Opened by Synaptic Stimulation in Single Hippocampal Spines
}

\author{
Esther A. Nimchinsky, Ryohei Yasuda, Thomas G. Oertner, and Karel Svoboda \\ Howard Hughes Medical Institute, The Cold Spring Harbor Laboratory, Cold Spring Harbor, New York 11724
}

The number of receptors opening after glutamate release is critical for understanding the sources of noise and the dynamic range of synaptic transmission. We imaged $\left[\mathrm{Ca}^{2+}\right]$ transients mediated by synaptically activated NMDA receptors (NMDA-Rs) in individual spines in rat brain slices. We show that $\mathrm{Ca}^{2+}$ influx through single NMDA-Rs can be reliably detected, allowing us to estimate the number of receptors opening after synaptic transmission. This number is small: at the peak of the synaptic response, less than one NMDA-R is open, on average. Therefore, stochastic interactions between transmitter and receptor contribute substantially to synaptic noise, and glutamate occupies a small fraction of receptors. The number of receptors opening did not scale with spine volume, and smaller spines experience larger $\left[\mathrm{Ca}^{2+}\right]$ transients during synaptic transmission. Our measurements further demonstrate that optical recordings can be used to study single receptors in intact systems.

Key words: NMDA receptor; synaptic transmission; calcium imaging; 2-photon; saturation

\section{Introduction}

Synaptic transmission at central synapses has often been treated as a stochastic process with two possible outcomes: neurotransmitter release, followed by a response with characteristic amplitude, or failure of neurotransmitter release. However, considerable evidence indicates that synaptic transmission has a large dynamic range. Studies in brain slices (Mainen et al., 1999a) and dissociated cultures (Liu et al., 1999; Umemiya et al., 1999; McAllister and Stevens, 2000) have revealed that synaptic receptors are not saturated by glutamate released in response to a single action potential. Synaptic transmission is, thus, not all-or-none, and there are additional factors that contribute to noise in synaptic transmission. First, trial-to-trial variations in the amount of glutamate released will lead to variations in the number of occupied receptors and the amplitudes of postsynaptic responses (McAllister and Stevens, 2000; Wadiche and Jahr, 2001; Oertner et al., 2002). Second, even for fixed glutamate release, stochastic interactions between transmitter molecules and receptors could produce additional variability in synaptic responses (Silver and Farrant, 1999); the relative contribution of this term to synaptic noise depends on the number of receptors opening after glutamate release, with smaller numbers producing larger fluctuations.

The number of receptors activated during synaptic transmis-

Received Nov. 15, 2003; revised Jan. 6, 2004; accepted Jan. 12, 2004.

This work was supported by the National Institutes of Health (E.A.N., K.S.), Burroughs Wellcome Fund (R.Y.), and Howard Hughes Medical Institute. We thank B. L. Sabatini, G. M. Shepherd, and S. Nelson for helpful suggestions, A. Sobczyk and other members of our laboratory for comments on this manuscript, and Peter $0^{\prime}$ Brien for technical help.

Correspondence should be addressed to Dr. Karel Svoboda, Howard Hughes Medical Institute, The Cold Spring Harbor Laboratory, 1 Bungtown Road, Cold Spring Harbor, NY 11724. E-mail: svoboda@cshl.edu.

E. A. Nimchinsky's present address: Center for Molecular and Behavioral Neuroscience, Rutgers, The State University of New Jersey, 197 University Avenue, Newark, NJ 07102.

T. G. Oertner's present address: Friedrich Miescher Institute, WRO-1066.4.10, Maulbeerstrasse 66, CH-4058 Basel, Switzerland.

DOI:10.1523/JNEUROSCI.5066-03.2004

Copyright $\odot 2004$ Society for Neuroscience $\quad$ 0270-6474/04/242054-11\$15.00/0 sion is unknown. Studies using electron microscopy (EM) have suggested that AMPA receptors (AMPA-Rs) and NMDA receptors (NMDA-Rs) are differentially distributed among central synapses and that there is considerable variability among synapses in their complement of receptors (Takumi et al., 1999; Racca et al., 2000). However, EM cannot provide information about functional receptors. Physiological estimates have relied on comparing spontaneous miniature EPSCs (mEPSCs) with the conductances of single receptors (Bekkers and Stevens, 1989; Spruston et al., 1995). It is not clear, however, where the synapses generating particular miniature currents are located in the dendritic tree. These currents are variably attenuated, and small miniature responses are not distinguishable from recording noise. Thus, it is not clear how the measurement of mEPSCs at the soma relate to the distributions of synaptic conductances in the dendritic tree (Magee and Cook, 2000), where most synapses are made. Moreover, electrophysiological methods cannot capture the rich heterogeneity of synaptic structure (Harris and Stevens, 1989; Harris et al., 1992; Schikorski and Stevens, 1997) and function (Murthy et al., 1997; Magee and Cook, 2000). In the case of NMDA-Rs, the number of receptors opening has additional importance because $\mathrm{Ca}^{2+}$ entering the synapse through this channel triggers diverse neuronal adaptive responses (Kleinschmidt et al., 1987; Bading et al., 1993; Cummings et al., 1996). Here, we use novel imaging assays to estimate the number of NMDA-Rs and AMPA-Rs opened during low-frequency synaptic transmission at single synapses.

\section{Materials and Methods}

Electrophysiology. Acute hippocampal slices (350 $\mu \mathrm{m}$ thick) were prepared from 16-18-d-old Wistar rats as described (Mainen et al., 1999a), in accordance with the animal care and use guidelines of Cold Spring Harbor Laboratory, using a cutting solution containing (in $\mathrm{mm}$ ) 110 choline chloride, $25 \mathrm{NaHCO}_{3}, 25$ D-glucose, 11.6 sodium ascorbate, 7 $\mathrm{MgSO}_{4}, 3.1$ sodium pyruvate, $2.5 \mathrm{KCl}, 1.25 \mathrm{NaH}_{2} \mathrm{PO}_{4}$, and $0.5 \mathrm{CaCl}_{2}$. 

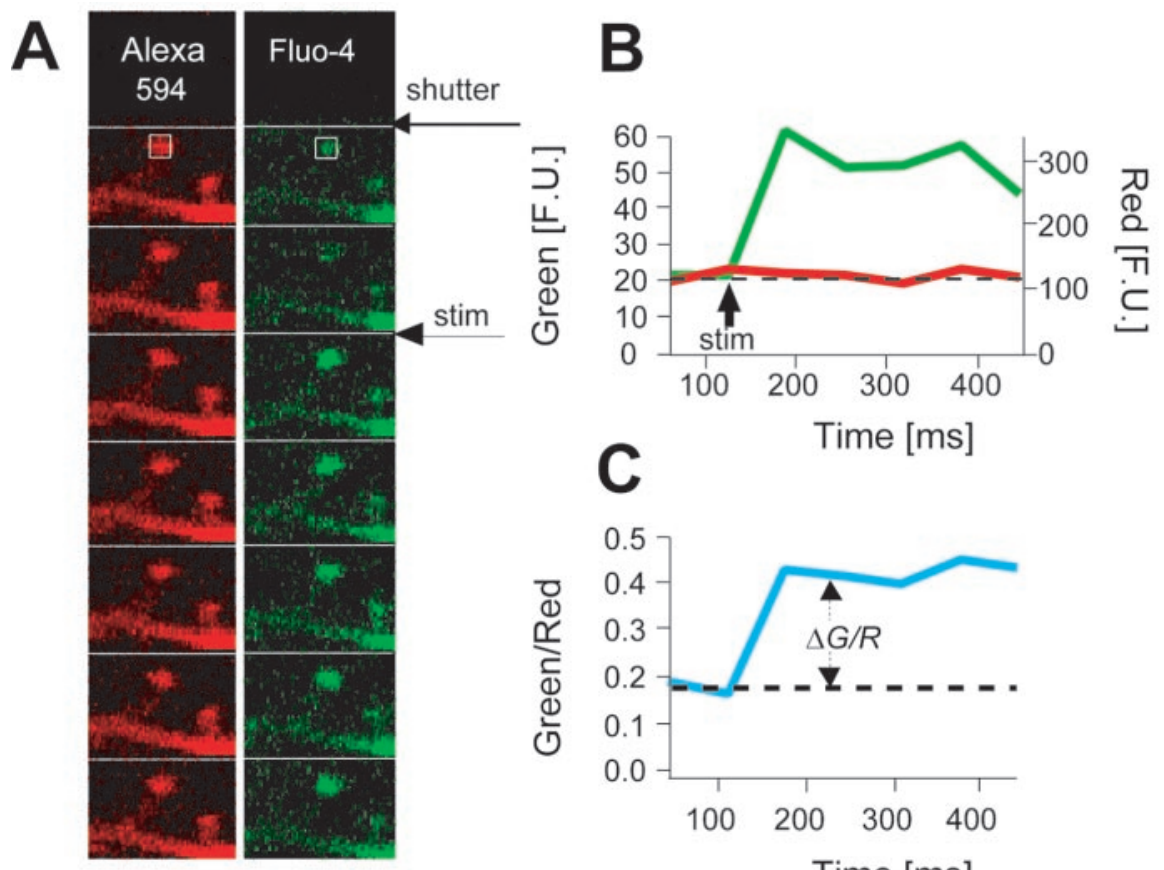

Imaging. We used a custom-built twophoton laser scanning microscope consisting of a Ti:sapphire laser (Mira; Coherent Radiation, Palo Alto, CA) tuned to $\sim 810 \mathrm{~nm}$, an Olympus (Lake Success, NY) objective [60×; numerical aperture (NA), 0.9], and a scan lens (Zeiss, Oberkochen, Germany) (Mainen et al., 1999b; Sabatini and Svoboda, 2000). Fluorescence was detected in epifluorescence and transfluorescence (through an oil-immersion condenser; NA, 1.4; Zeiss) modes using photomultiplier tubes (R3896; Hamamatsu Photonics, Hamamatsu, Japan). Image acquisition was controlled by custom software (Matlab; The Mathworks, Natick, MA) (Pologruto et al., 2003). In the transfluorescence pathway, a 565 $\mathrm{nm}$ dichroic mirror was used to separate green and red fluorescence. BG22 colored glass filters and 607/45 barrier filters were placed, respectively, in the "green" (shorter wavelength) and "red" (longer wavelength) pathways to eliminate transmitted or reflected excitation light (all filters and dichroics were from Chroma Technology, Brattleboro, VT). Stimulated synapses on second- to third-order apical dendrites were analyzed in frame scans with an online analysis program (B. Sabatini) written in IGOR Pro (Wavemetrics, Lake Oswego, OR) (Fig. 1).

To probe NMDA-R activation, we measured
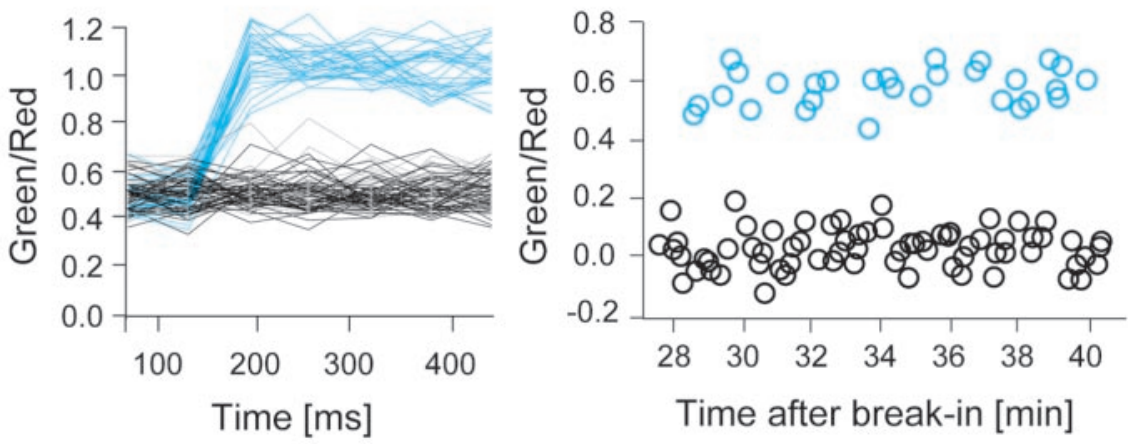

Figure 1. Two-photon $\left[\mathrm{Ca}^{2+}\right]$ imaging of NMDA-R activation in single dendritic spines. $A, A$ response in an individual spine imaged in frame-scan mode. A trial consists of a sequence of seven 64 msec images collected before ( 2 images) and after (5 images) delivery of the stimulus. The first image was collected before shutter opening to estimate the dark current. Left, Alexa 594, red; Right, Fluo-4, green (the region of interest is indicated by a white box). $B$, Fluorescence intensity measured in the region of interest in the green and red fluorescence channels. Note the absence of a change in fluorescence intensity in the red channel despite a dramatic change in the green channel in response to synaptic stimulation. F.U., Fluorescence units. C, Green/red ratio (blue trace) for the traces shown in $B$. These data are used for quantitative analysis. D, Representative set of trials from another spine, showing the clear separation between successes (blue) and failures (black). $E, \Delta G / R$ as a function of time.

Slices were incubated in gassed $\left(95 \% \mathrm{O}_{2} / 5 \% \mathrm{CO}_{2}\right)$ artificial CSF (ACSF) [containing (in mM): $127 \mathrm{NaCl}, 25 \mathrm{NaHCO}_{3}, 25$ D-glucose, $2.5 \mathrm{KCl}, 1.0$ $\mathrm{MgCl}_{2}, 2.0 \mathrm{CaCl}_{2}$, and $\left.1.25 \mathrm{NaH}_{2} \mathrm{PO}_{4}\right]$ at $34^{\circ} \mathrm{C}$ for $45-60 \mathrm{~min}$ and then at room temperature until used. Experiments were performed at $30^{\circ} \mathrm{C}$ in ACSF (flowing at 4-6 ml/min) containing 2,3-Dioxo-6-nitro-1,2,3,4tetrahydrobenzo[f] quinoxaline-7-sulfonamide (NBQX),bicuculline, and D-serine (10 $\mu \mathrm{M}$ each) to block AMPA-R- and $\mathrm{GABA}_{\mathrm{A}}$ receptormediated currents and glycine-dependent NMDA-R desensitization, respectively. In experiments using thapsigargin, slices were incubated in ACSF containing $1 \mu \mathrm{M}$ thapsigargin for at least $30 \mathrm{~min}$ before the establishment of whole-cell access. Whole-cell patch electrodes (2-6 M $\Omega$ ) contained (in mM) $135 \mathrm{CsMeSO}_{3}, 10 \mathrm{HEPES}, 10$ sodium phosphocreatine, 3 ascorbate, $4 \mathrm{MgCl}_{2}$, $4 \mathrm{Na}_{2}$-ATP, $0.4 \mathrm{Na}$-GTP, $0.075-0.150$ Fluo-4 or Fluo-5F or 0.5 Fluo-4FF, and 0.01-0.02 Alexa 594. Control measurements demonstrated that thapsigargin depleted intracellular stores, because it blocked caffeine-induced $\mathrm{Ca}^{2+}$ release (data not shown) (Garaschuk et al., 1997).
$\left[\mathrm{Ca}^{2+}\right]$ responses in single spines. CA1 pyramidal neurons were filled with a $\mathrm{Ca}^{2+}$ indicator [Fluo-4 $(150 \mu \mathrm{M})$ or Fluo-4FF $(500 \mu \mathrm{M})$ ] and a $\mathrm{Ca}^{2+}$-insensitive dye (Alexa 594 hydrazide; 40 $\mu \mathrm{M})$ through a patch pipette. Synapses were stimulated $(0.2 \mathrm{~Hz}, 0.2 \mathrm{msec}, 0.1$ to $-10 \mathrm{~V})$ using a monopolar glass extracellular stimulating electrode located $10 \mu \mathrm{m}$ from the target dendrite (Mainen et al., 1999a; Oertner et al., 2002). Each imaging trial consisted of eight sequential image frames, each $64 \mathrm{msec}$ in duration (Fig. 1A). After an initial frame taken with a closed shutter ("blank"), for measurement of the photomultiplier tube offset, the shutter was opened, and two frames were taken for an estimate of the baseline fluorescence intensity. A stimulus was then delivered, and five more frames were acquired, to allow monitoring of the $\left[\mathrm{Ca}^{2+}\right]$ signal for the first $320 \mathrm{msec}$ after the stimulus. $\left[\mathrm{Ca}^{2+}\right]$ transients were quantified by measuring the ratio of the $\mathrm{Ca}^{2+}$-sensitive fluorescence signal (green channel) to the $\mathrm{Ca}^{2+}$ insensitive signal (red channel) in a region of interest in the head of the spine, as defined by the red channel, for the first two frames after stimulation (Yasuda et al., 2004). The change in fluorescence after stimulation was calculated by subtracting the mean fluorescence value of the two frames before the stimulus from the mean fluorescence value of the second through the fourth frames after the stimulus, normalized to red fluorescence $(\Delta G / R)$.

Once an active synapse was found, as judged by $\Delta G / R>0$, stimulation intensity was increased to avoid stimulation failures. For imaging trials, the cell was held close to the reversal potential $(\sim+10 \mathrm{mV})$. For measurements of NMDA-R-mediated whole-cell currents during a fraction of interleaved trials, the cell was held $40 \mathrm{mV}$ positive to the reversal potential. Additional trials consisting of imaging without synaptic stimulation were also interleaved, to obtain a $\Delta G / R$ distribution of true "failures" (Figs. $2 B, C, 6 A, B$, red bars). Amplitudes of NMDA-R-mediated EPSCs were measured in a window 10-14 msec after the stimulus. One synapse was analyzed by failure analysis per neuron. For measurements of the effect of 3-(CR)-2-Carboxypiperazin-4-yl)-propyl-1-phosphonic 
A

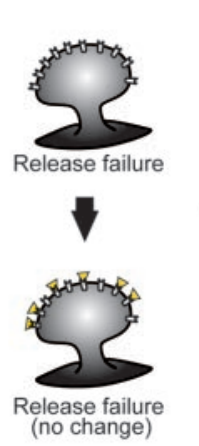

B

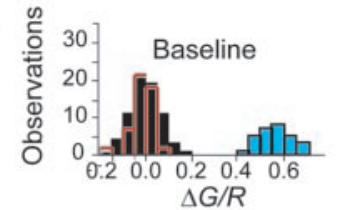

D

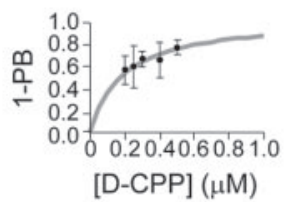

F

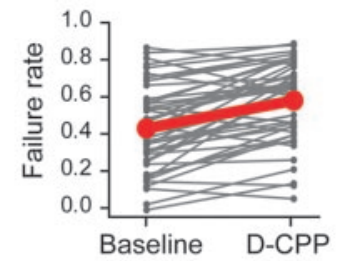

H

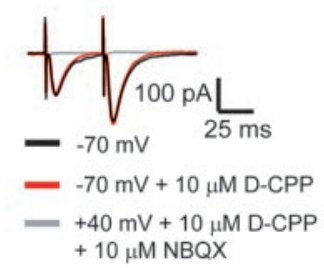

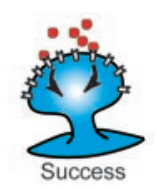
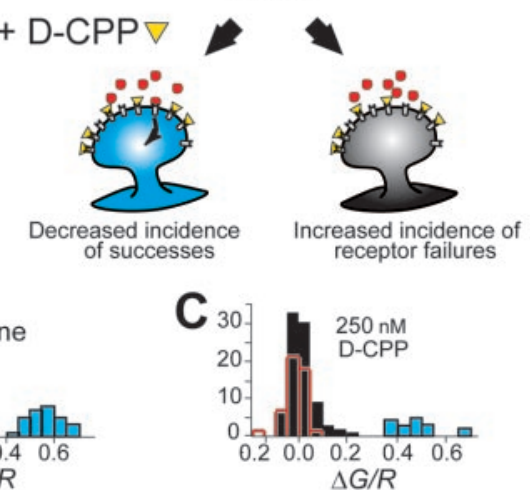

E
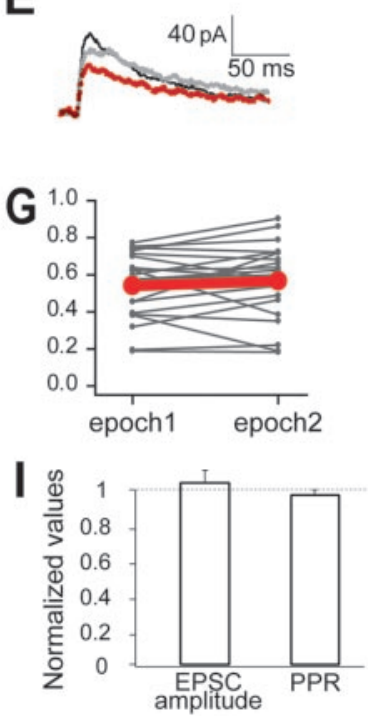

Figure 2. Detection of failures of receptor activation. $A$, Schematic illustrating the failure analysis in single dendritic spines using the high-affinity indicator Fluo-4. Under baseline conditions (top), presynaptic stimulation results in failures, primarily because of failure of neurotransmitter release and successes attributable to binding of released glutamate to NMDA-Rs and the resultant influx of $\mathrm{Ca}^{2+}$ (arrows). Under conditions of partial NMDA-R blockade, the incidence of release failures does not change but there is an increased incidence of failures of receptors to open despite glutamate release (receptor failures), at the expense of successes. Note that under these conditions, successes are attributable to the opening of fewer channels and often a single channel. Because of dye saturation, these responses appear nearly as large as responses attributable to the opening of many channels. $B, C$, Frequency distributions of NMDAR-mediated $\mathrm{Ca}^{2+}$ signals before $(B)$ and in the presence of ( $C$ D-CPP. Note the clear separation of successes (blue bars) from failures (black bars) in both conditions. Under conditions of partial blockade, failures increased at the expense of successes. Open histograms (red) indicate the distribution of $\Delta G / R$ in trials when no stimulus was delivered. $D$, Partial blockade (PB) of NMDA-R EPSCs as a function of [D-CPP]. The gray line shows the fit using the Michaelis-Menten equation. E, NMDA-R EPSCs (black line; baseline) partially blocked by $250 \mathrm{~nm}$ D-CPP (red line). The washout trace is indicated by the gray line. These currents are from the same experiment illustrated in $A$ and $B . F, G, D$-CPP increases failure rates. $F$, Synapses $(N=45)$ that were recorded before and after the addition of D-CPP showed a mean net change of $34 \%$ (red bar). In comparison, $G$ shows the analogous data from 15 synapses in which D-CPP was not added, to test for nonstationarity of $f$. When divided into epochs analogous to "baseline" and "D-CPP" epochs analyzed in the failure analysis, there was no net change in $f$ (red bar). $H, I$, Absence of a presynaptic effect of D-CPP. $H$, Black trace, baseline at $-70 \mathrm{mV}$; red trace, $10 \mu \mathrm{m}$ D-CPP at -70 $\mathrm{mV}$; gray trace, $10 \mu \mathrm{m} \mathrm{D}$-CPP plus $10 \mu \mathrm{m}$ NBQX at $+40 \mathrm{mV}$, demonstrating complete blockade of the NMDA-REPSC at this concentration of D-CPP. I, D-CPP $(10 \mu \mathrm{m})$ does not have an effect on AMPA-R EPSC amplitude or paired-pulse ratio (PPR) (ISI, $40 \mathrm{msec}$ ).

Table 1. Parameters used in the model

\begin{tabular}{|c|c|c|c|}
\hline Parameter & Definition & Value & Reference \\
\hline$R$ & Gas constant & $8.315 \mathrm{JK}^{-1} \mathrm{~mol}^{-1}$ & \\
\hline$T$ & Absolute temperature & $303 \mathrm{~K}$ & \\
\hline$F$ & Faraday constant & $9.6510^{4} \mathrm{C} \mathrm{mol}^{-1}$ & \\
\hline$e$ & Elementary charge & $1.6010^{-19} \mathrm{C}$ & \\
\hline$N_{\mathrm{A}}$ & Avogadro number & $6.0210^{23} \mathrm{~mol}^{-1}$ & \\
\hline$V_{s p}$ & $\begin{array}{l}\text { Spine volume } \\
\text { NMDA-R permeability of } \mathrm{Ca}^{2+} /\end{array}$ & $0.08 \mathrm{fL}$ & Harris and Stevens (1989) \\
\hline$P_{\mathrm{Ca}} / P_{\mathrm{M}}$ & Permeability of monovalent ions & 3.6 & Spruston et al. (1995) \\
\hline $\begin{array}{l}\gamma \\
{\left[\mathrm{M}^{+}\right]}\end{array}$ & $\begin{array}{l}\text { Conductance of monovalent ions } \\
\text { Concentration of monovalent ions }\end{array}$ & $\begin{array}{l}46 \mathrm{pS} \\
130 \mathrm{~mm}\end{array}$ & Spruston et al. (1995) \\
\hline$\left[\mathrm{Ca}^{2+}\right]_{\mathrm{ex}}$ & $\begin{array}{l}\text { External }\left[\mathrm{Ca}^{2+}\right] \\
\mathrm{Ca}^{2+} \text { clearance rate constant in }\end{array}$ & $2.0 \mathrm{~mm}$ & \\
\hline$k_{\mathrm{ex}}$ & the absence of $\mathrm{Ca}^{2+}$ buffer & $1.6 \mathrm{msec}^{-1}$ & Sabatini et al. (2002) \\
\hline$\kappa_{\mathrm{i}}$ & Endogenous buffer capacity & 20 & Sabatini et al. (2002) \\
\hline$K_{\mathrm{d}}$ & Dissociation constant of dye & $\begin{array}{l}9.7 \mu \mathrm{M} \text { for Fluo- } \\
4 \mathrm{FF}\end{array}$ & $\begin{array}{l}\text { Oertner et al. (2002) } \\
\text { Molecular Probes Hand- } \\
\text { book of Fluorescent } \\
\text { Probes and Research } \\
\text { Products }\end{array}$ \\
\hline$[\text { dye }]_{\text {Total }}$ & Total dye added & $\begin{array}{l}150 \mu \mathrm{m} \text { for Fluo-4 } \\
500 \mu \mathrm{m} \text { for Fluo- } \\
\quad 4 \mathrm{FF}\end{array}$ & \\
\hline$p_{0}$ & Open probability & 0.3 & Dzubay and Jahr (1996) \\
\hline$\tau_{\text {Poisson }}$ & Average open time & $100 \mathrm{msec}$ & Figure $2 E$ \\
\hline
\end{tabular}

acid (D-CPP) on AMPA-R EPSCs, cells were held at $-70 \mathrm{mV}$, and NBQX was omitted from the bath. Paired stimuli were delivered via a tungsten bipolar stimulating electrode [interstimulus interval (ISI), $40 \mathrm{msec}$ ]. AMPA-R currents were measured in a window 5-8 msec after the stimulus. For measurement of AMPA-R/NMDA-R ratios, baseline trials (black trace) were taken at $40 \mathrm{mV}$ positive to the reversal potential. Then, $10 \mu \mathrm{M}$ D-CPP was added, and additional trials were obtained (AMPA-R component). The trace in the presence of $\mathrm{D}$-CPP was subtracted from that in its absence to obtain the NMDA-R component. The peak amplitudes of the AMPA-R and NMDA-R components were computed for the AMPA-R/NMDA-R ratio. The response remaining after D-CPP was eliminated by $10 \mu \mathrm{M}$ NBQX.

Biophysical model of NMDA-R-mediated $\mathrm{Ca}^{2+}$ accumulations. A realistic model was constructed in Matlab (The MathWorks). We used the Goldman-Hodgkin-Katz equation as a simple model that reasonably approximates important behaviors of the NMDA-R, such as the linearity of the $I-V$ curve when there is no $\mathrm{Mg}^{2+}$ block and the shape of the $I-V$ curve when $\mathrm{Ca}^{2+}$ is added (Jahr and Stevens, 1993; Spruston et al., 1995).

Calcium influx from a single NMDA-R is given as (assuming reversal potential $=0$ ):

$I_{\mathrm{Ca}}=-4\left(P_{\mathrm{Ca}} / P_{\mathrm{M}}\right) V \gamma\left(\left[\mathrm{Ca}^{2+}\right]_{\mathrm{ex}} /\left[\mathrm{M}^{+}\right]\right) \exp (-2 V F / R T) /(1-\exp$

$$
(-2 V F / R T)) \text {, }
$$

where $R$ is the gas constant, $T$ is absolute temperature, $F$ is Faraday's constant, $P_{\text {ca }}$ is the permeability of $\mathrm{Ca}^{2+}, P_{\mathrm{M}}$ is permeability of monovalent ions, $\left[\mathrm{Ca}^{2+}\right]_{\mathrm{ex}}$ is external $\mathrm{Ca}^{2+}$ concentration, $\left[\mathrm{M}^{+}\right]$is the concentration of monovalent ions (assuming the same for external and internal saline), and $\gamma$ is the conductance for monovalent ions (Table 1).

Thus, at the reversal potential $(V=0 \mathrm{mV})$ :

$$
I_{\mathrm{Ca}}=-4\left(P_{\mathrm{Ca}} / P_{\mathrm{M}}\right)\left(\left[\mathrm{Ca}^{2+}\right]_{\mathrm{ex}} /\left[\mathrm{M}^{+}\right]\right) \gamma R T / 2 F .
$$

The increase in total $\mathrm{Ca}^{2+}$ concentration, $\left[\mathrm{Ca}^{2+}\right]_{\mathrm{T}}$, per unit time during the channel opening is obtained as:

$$
a=I_{\mathrm{Ca}} /\left(2 e V_{\mathrm{sp}} N_{\mathrm{A}}\right),
$$

where $V_{\mathrm{sp}}$ is spine volume, $N_{A}$ is Avogadro number, and $e$ is elementary charge. 
The time courses of free intracellular $\mathrm{Ca}^{2+}$ concentration, $\left[\mathrm{Ca}^{2+}\right]$, and $\left[\right.$ dye $\left.\mathrm{Ca}^{2+}\right]$, where $\left[\mathrm{Ca}^{2+}\right]_{\mathrm{T}}=\left[\mathrm{Ca}^{2+}\right]+\left[\right.$ dye $\left.\mathrm{Ca}^{2+}\right]$, were solved numerically using the following equations:

$$
\begin{gathered}
d\left[\mathrm{Ca}^{2+}\right]_{\mathrm{T}} / d t=\left(I_{\mathrm{Ca}}(t)-k_{\text {ex }}\left[\mathrm{Ca}^{2+}\right]\right) / \\
\left(1+\kappa_{\mathrm{i}}+[\text { dye }]_{\text {Total }} K_{\mathrm{d}} /\left(K_{\mathrm{d}}+\left[\mathrm{Ca}^{2+}\right]\right)^{2}\right) \\
{\left[\text { dye Ca }{ }^{2+}\right]=[\text { dye }]_{\text {Total }}\left[\mathrm{Ca}^{2+}\right] /\left(K_{\mathrm{d}}+\left[\mathrm{Ca}^{2+}\right]\right),}
\end{gathered}
$$

where $K_{\mathrm{d}}$ is dissociation constant of dye, $k_{\mathrm{ex}}$ is the extrusion rate, $\kappa_{\mathrm{t}}$ is the intrinsic buffer capacity, and $[\mathrm{dye}]_{\text {Total }} K_{\mathrm{d}} /\left(K_{\mathrm{d}}+\left[\mathrm{Ca}^{2+}\right]\right)^{2}$ is the added buffer capacity (Neher and Augustine, 1992). $\mathrm{Ca}^{2+}$ influx $I_{\mathrm{Ca}}(t)$ is approximated as:

$$
I_{\mathrm{Ca}}(t)=p_{\mathrm{o}} a\left(0<t<t_{\mathrm{o}}\right)=0\left(t>0, t_{\mathrm{o}}<t\right),
$$

where $p_{o}$ is open probability and $t_{\mathrm{o}}$ is open time of NMDA-R and distributed as $\exp \left(-t_{\mathrm{o}} / \tau_{\text {Poisson }}\right)$. For each trial and each channel, $t_{\mathrm{o}}$ was randomly selected from the exponential distribution. The number of channels open in each trial was selected randomly assuming the Poisson distribution.

In some simulations (Fig. 3, dashed lines), fluctuations in $n$ attributable to variability of glutamate concentration in the cleft and location of glutamate release ("configuration") was taken into account. Based on published computational studies, we made the conservative assumption that $n$ is distributed normally with a large coefficient of variation (CV) (0.58) (Franks et al., 2003),

$$
P(n) \mathrm{d} n=\exp \left(-(n-\langle n\rangle)^{2} /(0.58\langle n\rangle)^{2}\right) \mathrm{d} n,
$$

where $\langle n\rangle$ is the average over configurations. We assigned $n$ randomly from this distribution.

Release probability was set at 1 (i.e., failures are attributable to receptor failures). Shot noise was included in the model by estimating a typical value for photon numbers for a single time point as 100 (Table 2).

Failure analysis for measuring the number of receptors opening, $n$. We measured the failure probability $f$. Failures consist of two experimentally indistinguishable types of trials: those in which neurotransmitter is not released, defined as $1-P_{r}$ (where $P_{r}=$ the probability to release at least one quantum), and those in which receptors fail to open despite neurotransmitter release, defined as $P_{r}\left(1-p_{r o}\right)^{\mathrm{M}}$, where $p_{r o}$ is the probability that a synaptic receptor opens given neurotransmitter release, and $M$ is the number of receptors present at the synapse and available for binding (Table 2). It should be emphasized that $p_{r o}$ is a property of synapses and is, therefore, fundamentally different than the concept of "open probability $\left(p_{o}\right)$ " used in studies of NMDA-R function, which refers to the fraction of time receptors open when bound to glutamate. The probability of failures in the absence of drug is given by:

$$
f=\left(1-P_{r}\right)+P_{r}\left(1-p_{r o}\right)^{\mathrm{M}} .
$$

Partial NMDA-R blockade was achieved by rapidly adding D-CPP to the perfusion system while measuring EPSC amplitudes. We use D-CPP because of its high specificity for NMDA-Rs and because of its dwell time on the NMDA-R $\left(k_{\text {off }}{ }^{-1} ; \sim 1 \mathrm{sec}\right)$, which is long compared with the duration of the glutamate transient in the cleft $(\sim 1 \mathrm{msec})$ but short compared with the ISI $(5-10 \mathrm{sec})$. Therefore, subsequent stimulus trials probe a different subset of NMDA-Rs. After equilibration with D-CPP (5-10 min), imaging was resumed (D-CPP). In cases in which the distributions of successes and failures overlapped after the addition of D-CPP, the distribution of responses recorded in the absence of a stimulus (Fig. $2 B, C$, red bars) was scaled to the distribution of responses in the presence of a stimulus, and the number of responses in this distribution was taken as the number of failures. In the presence of D-CPP, receptors are blocked in a stochastic manner with a probability of $\left(1-I^{\prime} / I\right)$, where $I$ and $I^{\prime}$ represent the amplitudes of the whole-cell NMDA-R currents, before and after drug, respectively. $I$ and $I^{\prime}$ were determined for each experiment. In antagonist, the probability of a failure is:

$$
f^{\prime}=\left(1-P_{r}\right)+P_{r}\left(1-p_{r o} I^{\prime} / I\right)^{M} .
$$

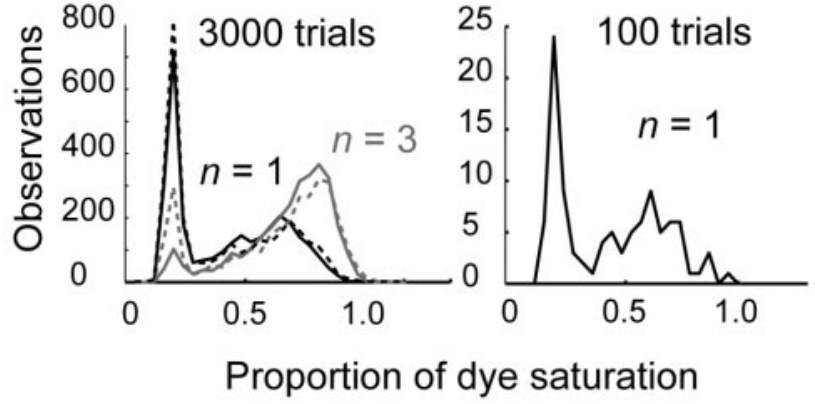

Figure 3. Results of simulations of NMDA-R activation reported by Fluo-4 (150 $\mu \mathrm{m})$ with 3000 (left) or 100 (right) trials. Response amplitudes are expressed as the proportion of dye saturation. Parameters are given in Table $1 ; P_{r}=1$. Two separate peaks are apparent, corresponding to successes and failures, even when only one receptor is opening, on average $(n=1$; black lines). Note that when $n$ increases from 1 to 3 (gray lines), the number of failures decreases, as expected. Dashed lines indicate simulations taking into account the variability of glutamate concentration in the cleft and of the location of glutamate release (see Materials and Methods). Note the slight increase in failures when this variability is taken into account.

The average number of receptors that open after neurotransmitter release is $n=M P_{r o}$. In the Poisson limit, $\left(1-P_{r o}\right)^{M} \approx e^{-P \text { roM }}$, and combining Equations 2 and 3, we arrive at the relationship:

$$
\frac{1-f}{1-e^{-n}}-\frac{1-f^{\prime}}{1-e^{-n I^{\prime} / I}}=0 \text {. }
$$

We solve this equation for $n$ numerically using Newton's method. $P_{r}$ was obtained as $(1-f) /\left(1-e^{-n}\right)$. Because only a finite number of trials can be collected per condition $(s, \sim 100)$ the error in $n, \delta$ n, is dominated by errors in the estimation of $f$ and $f^{\prime}$. Hence:

$$
\delta n \sim|\delta n / \delta f| \cdot|\delta f|+\left|\delta n / \delta f^{\prime}\right| \cdot\left|\delta f^{\prime}\right|,
$$

where $\delta \mathrm{f}$ and $\delta \mathrm{f}^{\prime}$ are errors of $f$ and $f^{\prime}$. These are given by the binomial distribution as:

$$
\delta f=[(1-f) f s]^{1 / 2}, \delta f^{\prime}=\left[\left(1-f^{\prime}\right) f^{\prime} s\right]^{1 / 2} .
$$

In Equation $11,(\delta \mathrm{n} / \delta \mathrm{f})$ and $\left(\delta \mathrm{n} / \delta \mathrm{f}^{\prime}\right)$ are obtained from Equations 8 and 9 as:

$$
|\delta n / \delta f| \sim e^{\mathrm{n}} P_{r}^{-1},\left|\delta n / \delta f^{\prime}\right| \sim\left(I / I^{\prime}\right) \cdot e^{\mathrm{n}} P_{r}^{-1},
$$

where $P_{r}$ is given by $(1-f) /\left(1-e^{-n}\right)$. Thus:

$$
\delta n \sim e^{n} P_{r}^{-1}|\delta f|+I / I^{\prime} e^{n I^{\prime} / I} P_{r}^{-1}\left|\delta f^{\prime}\right| .
$$

Because the error is asymmetric, we also calculated upper and lower limits using the errors calculated using $I+\delta I, I^{\prime}-\delta I^{\prime}, f+\delta f, f^{\prime}-\delta f^{\prime}$, and $I-\delta I, I^{\prime}+\delta I^{\prime}, f-\delta f, f^{\prime}+\delta f^{\prime}$ in Equation 10 , respectively. $\delta I$ and $\delta I^{\prime}$ are SEM of $I$ and $I^{\prime} . \delta f$ and $\delta f^{\prime}$ are obtained from Equation 14.

We also calculated $n$ without the approximation $\left(1-p_{r o}\right)^{M} \approx e^{-n}$. Because $n$ depends on $p_{r o}$ in this case, the range of possible values of $p_{r o}$ $(0-0.6)$ (Mainen et al., 1999a) gives a range of $n$. The mean maximal error due to this approximation across all synapses in which a value could be computed was only $0.087 \pm 0.016(N=27)$, confirming that the Poisson approximation is valid for this analysis.

In our calculation, the trial-to-trial variability in glutamate concentration in the synaptic cleft and the location of glutamate release is constant. To justify this assumption, we quantified the effects of trial-to-trial variability both in glutamate concentration and in the position of the release site relative to the postsynaptic density (PSD). Assuming that $n$ is distributed normally because of the variable configuration (Eq. 7), we drew $n$ 100,000 times from the distribution to calculate the failure rate when 


\section{Table 2. Frequently used variables}

\begin{tabular}{ll}
\hline Variable & Definition \\
\hline$f$ & Failure rate before addition of drug \\
$f^{\prime}$ & Failure rate after addition of drug \\
$l$ & Whole-cell current before addition of drug \\
$l^{\prime}$ & Whole-cell current after addition of drug \\
$P_{r o}$ & Probability of a receptor opening during a trial, given neurotransmitter release \\
$P_{r}$ & Probability of presynaptic neurotransmitter release \\
$n$ & Number of NMDA-R molecules opening at a single synapse \\
$M$ & Number of NMDA-R molecules at a single synapse \\
\hline
\end{tabular}

glutamate is released as $f_{\text {channel }}=\left(1-p_{\text {ro }}\right)=\left\langle e^{-n}\right\rangle$ as a function of $\langle n\rangle$. $\langle n\rangle$ was obtained from the following equation:

$$
\frac{1-f}{1-f_{\text {channel }}(\langle n\rangle)}-\frac{1-f^{\prime}}{\left.1-f_{\text {channel }}\left(\langle n\rangle I^{\prime} / I\right)\right)}=0 \text {. }
$$

$\langle n\rangle$ derived in this manner differed from $n$ obtained by Equation 2 only by $0.15 \pm 0.03(n=31)$, well within our error bars.

We estimated the error in our calculation of $n$ because of possible random fluctuations in $P_{r}$. We measured the failure rate in a series of sliding windows, ranging in size from 10 to 100 trials, with $50 \%$ overlap between consecutive windows. The CV of $f$ was plotted as a function of window size. This was repeated in simulations with a fixed $P_{r}$. As expected, the $\mathrm{CV}$ in both experiments and simulations declined with increasing window size. We noticed that the CV in experiments was somewhat higher than in simulations ( $45 \%$ at a representative window size of 80 ), indicating that $P_{r}$ fluctuates. However, this nonstationarity is too small to affect the results from the failure analysis.

Amplitude analysis for measuring $n$. To measure $\Delta G / R$ of successes in a linear regime, experiments were performed with Fluo-4FF $\left[K_{\mathrm{d}} \sim 9.7 \mu \mathrm{M}\right.$ according to the Molecular Probes (Eugene, OR) Handbook of Fluorescent Probes and Research Products; our own estimate, measured under physiological conditions, ranged from 6.9 to $13 \mu \mathrm{M})$. The distribution of response amplitudes recorded in the absence of a stimulus (see Fig. $6 A, B$, red bars) was scaled to the distribution of responses in the presence of a stimulus, and the number of responses in this distribution was taken as the number of failures. The mean $\Delta G / R$ of successes $(<\Delta G / R\rangle)$ was then calculated as the mean $\Delta G / R$, multiplied by the total number of trials and divided by the total number of successes. In six experiments, it was possible to perform a failure analysis (above) to measure $n$. Because under these conditions $\Delta G / R$ is a linear reporter of $\left[\mathrm{Ca}^{2+}\right]$ transients, $<\Delta G / R>$ is proportional to $n$, such that $\left\langle\Delta G / R>=c n / V_{\mathrm{sp}}\right.$. Here, $V_{\mathrm{sp}}$ is the measured spine volume (range, $0.009-0.038 \mathrm{fL}$; mean, $0.021 \mathrm{fL}$ ), and $c$ is the change in fluorescence produced by the opening of a single channel in a unit volume. For another set of spines $(N=15), n$ was obtained using amplitude information alone, because $n=\langle\Delta G / R\rangle V_{s p} / c$. Correlations were tested using the Pearson correlation coefficient with an $\alpha$ level of 0.05 .

Estimation of spine volume. Because spines are below the resolution of the optical system as defined by the point spread function (PSF; mean spine head volume for the largest class of spines $=0.16 \pm 0.08 \mathrm{fL}$ ) (Harris et al., 1992), the brightness of a spine is proportional to its volume, assuming homogeneously distributed dye. The spine volume can, therefore, be estimated by obtaining the ratio of the peak spine brightness (measured as the mean of the pixels at the brightest point of the spine image) to the peak brightness of a field contained completely within a larger volume, such as the proximal apical dendrite. This value, multiplied by the volume of the PSF ( $0.3 \mathrm{fL}$; measured by imaging $200 \mathrm{~nm}$ fluorescent plastic beads in a comparable hippocampal acute slice, with the edges of their volume defined as the width of the image at halfmaximum intensity), gives the spine volume in femtoliters. To correct for the attenuation of the signal with depth, 10 thick apical dendrites were imaged, and their fluorescence was measured at $5 \mu \mathrm{m}$ intervals in the $z$ direction. The decrease in intensity with depth and the SEM across dendrites was computed, yielding a correction factor \pm SEM. The difference in depth between individual spines and the site where the PSF was ob- tained was measured, the brightness was then multiplied by the depthappropriate correction factor, and the SEM of the volume estimate was computed as $2 \cdot$ SEM for brightness. In all cases, the spine was deeper than the site where the intensity of the PSF volume was obtained (range, 0-35 $\mu \mathrm{m})$. The intensity at the mean depth difference $(12.7 \mu \mathrm{m})$ was $0.75 \pm$ 0.09 of the value at a relative depth of 0 .

\section{Results}

To estimate the number of synaptic NMDA-Rs opening during synaptic transmission, it is necessary to probe transmission at individual synapses. The vast majority of excitatory synapses in the CNS occur on dendritic spines, tiny dendritic protrusions (volumes, $\sim 0.1 \mu \mathrm{m}^{3}$ ) (Nimchinsky et al., 2002) that subserve synapse-specific $\mathrm{Ca}^{2+}$ signaling (Yuste and Denk, 1995; Sabatini et al., 2002). $\left[\mathrm{Ca}^{2+}\right]$ responses in single spines can be measured as a reporter of synaptic NMDA-R activation at single synapses (Mainen et al., 1999a; Kovalchuk et al., 2000; Oertner et al., 2002). We used this approach to measure the number of NMDA-Rs opening in response to synaptic stimulation.

A previous study using optical fluctuation analysis demonstrated our ability to detect optically the opening of single voltage-sensitive $\mathrm{Ca}^{2+}$ channels (VSCCs) during an action potential (Sabatini and Svoboda, 2000). These channels remain open for $\sim 0.2 \mathrm{msec}$ and have a conductance of $\sim 10 \mathrm{pS}$, with all of the charge carried by $\mathrm{Ca}^{2+}$. NMDA-Rs have smaller conductance for $\mathrm{Ca}^{2+}$ ( $\sim 5 \mathrm{pS} ; 10 \%$ of monovalent ions) (Jahr and Stevens, 1993) but much longer open times, reflecting the slow unbinding of glutamate $(\sim 100 \mathrm{msec})$ (Lester et al., 1990). The total $\mathrm{Ca}^{2+}$ influx produced by the opening of an NMDA-R is larger than that produced by the opening of a VSCC, by more than an order of magnitude. Thus, we should be able to detect the opening of a single NMDA-R. A more detailed analysis is described below.

To probe NMDA- $\mathrm{R}$ activation, we measured $\left[\mathrm{Ca}^{2+}\right]$ responses in single spines. CA1 pyramidal neurons were filled with $\mathrm{a} \mathrm{Ca}^{2+}$ indicator [Fluo-4 $(150 \mu \mathrm{M})$ or Fluo-4FF $(500 \mu \mathrm{M})$ ] and a $\mathrm{Ca}^{2+}$-insensitive dye (Alexa 594 hydrazide; $40 \mu \mathrm{M}$ ) through a patch pipette. Synaptic transmission was evoked with an extracellular stimulation pipette (Mainen et al., 1999a; Oertner et al., 2002). Fluorescence changes in dendritic spines, produced by synaptically evoked $\left[\mathrm{Ca}^{2+}\right]$ transients, were measured with twophoton laser scanning microscopy (Denk et al., 1990; Denk and Svoboda, 1997) and expressed as the change in green $\left(\mathrm{Ca}^{2+}\right.$ sensitive dye) fluorescence, normalized to the red $\left(\mathrm{Ca}^{2+}\right.$ insensitive dye) fluorescence, $\Delta G / R$ (Fig. $1 A-C$ ). To isolate $\left[\mathrm{Ca}^{2+}\right]$ transients mediated by NMDA-Rs, the postsynaptic membrane was depolarized close to the reversal potential $(\sim 10$ $\mathrm{mV}$ ). At these holding potentials, VSCCs inactivate (Magee and Johnston, 1995), the $\mathrm{Mg}^{2+}$ block of NMDA-Rs is relieved (Spruston et al., 1995), and synaptic transmission does not carry net synaptic current. $\left[\mathrm{Ca}^{2+}\right]$ transients were blocked completely by antagonists of NMDA-Rs ( $10 \mu \mathrm{M}$ D-CPP; $96 \pm 4 \%$ block; $N=3)$. Experiments performed with and without the presence of drugs that deplete stores gave identical results (see below), confirming that $\mathrm{Ca}^{2+}$ release from stores does not contribute to our $\left[\mathrm{Ca}^{2+}\right]$ transients (Mainen et al., 1999a; Kovalchuk et al., 2000; Sabatini et al., 2002). We conclude that under our experimental conditions $\left[\mathrm{Ca}^{2+}\right]$ transients in individual spines report NMDA-R activation at single synapses.

\section{Detecting receptor failures during synaptic transmission}

For each synapse, we measured large numbers of $\left[\mathrm{Ca}^{2+}\right]$ responses to synaptic stimulation. When imaged with a highaffinity dye (Fluo-4), NMDA-R-mediated $\left[\mathrm{Ca}^{2+}\right]$ transients pro- 
duced large amplitude fluorescence changes clearly distinguishable from failures (Fig. $1 B-E$ ). Note that although the use of a high-affinity dye ensures that even the smallest events are reliably detected, the variance in the amplitudes of responses (Fig. $1 D$ ) is artificially reduced by dye saturation. Stimuli randomly produced failures and successes of NMDA-R-mediated $\left[\mathrm{Ca}^{2+}\right]$ accumulations in dendritic spines, reflecting the stochastic nature of neurotransmitter release. Failures of $\left[\mathrm{Ca}^{2+}\right]$ transients in spines with probability $f$ consist of two indistinguishable events (Fig. 2A): (1) failure to release glutamate (release failures) and (2) failure to open even a single NMDA-R despite glutamate release (receptor failures). Receptor failures will occur rarely unless only a small number of receptors open, on average. However, reducing the number of receptors available for glutamate binding, by adding subsaturating concentrations of a high affinity-antagonist of NMDA-Rs to the bath, should make failures more probable. In the absence of presynaptic effects (see below), such manipulations would selectively cause an increase in receptor failures.

To test this idea, we collected an epoch (60-100 trials) of $\left[\mathrm{Ca}^{2+}\right]$ responses to synaptic stimulation under baseline conditions (Fig. $1 D, E, 2 B$ ). We then added a subsaturating dose of $\mathrm{D}$-CPP and waited until it equilibrated within the slice $(\sim 5 \mathrm{~min})$, after which a second epoch of trials was collected (Fig. 2C). Remarkably, even modest concentrations of antagonist (250-400 $\mathrm{nM}$ ), producing 30-60\% block (Fig. $2 D, E$ ), were often sufficient to increase the incidence of receptor failures (average change in failure rate, 34\%) (Fig. 2 F). In contrast, in the absence of D-CPP, failure probabilities were stable over time ( $\sim 10 \mathrm{~min} ; 80$ trials), as judged by comparing the failure probabilities computed over successive epochs of trials (Fig. 2G).

We interpret the observed increase in failures with D-CPP as evidence for failures of receptor opening after glutamate release. An alternative explanation could be that application of D-CPP reduces the amplitudes of NMDA-R-mediated $\left[\mathrm{Ca}^{2+}\right]$ transients, driving some release events below detection threshold. The additional failures in the presence of drug would, in other words, be failures of detection, not of receptor opening. To determine whether lowered $\mathrm{Ca}^{2+}$ influx per se could translate into apparent changes in the failure rate, we reduced the driving force for $\mathrm{Ca}^{2+}$ by clamping neurons at more positive potentials, thereby reducing $\mathrm{Ca}^{2+}$ influx without changing the failure rate (Schneggenburger et al., 1993). Using a low-affinity dye as a linear reporter of $\left[\mathrm{Ca}^{2+}\right]\left(500 \mu \mathrm{M}\right.$ Fluo-4FF; $\left.K_{\mathrm{d}}=9.7 \mu \mathrm{M}\right)$, we determined that a $20 \mathrm{mV}$ increase in the holding potential decreases $\mathrm{Ca}^{2+}$ influx by $\sim 65 \%$, more than the fractional block of NMDA-Rs in the experiments described above (range, 30-60\%). In experiments using the high-affinity dye Fluo-4, we then interleaved trials at reversal potential and at $20 \mathrm{mV}$ positive to the reversal potential and computed the respective failure rates. Measured failure rates were identical at both potentials (mean overall failure rates for five synapses were $0.60 \pm 0.11$ at reversal and $0.62 \pm 0.08$ at $20 \mathrm{mV}$ above reversal; $p>0.05$ ), indicating that increased failure rates in D-CPP are not attributable to detection problems.

Another possible confound could be presynaptic NMDA-Rs (Casado et al., 2002; Sjostrom et al., 2003). Blocking these receptors could alter release probability without changing receptor failures. To test for effects of NMDA-R blockade on release probability, we measured AMPA-R-mediated whole-cell currents as a measure of glutamate release. Even saturating concentrations (10 $\mu \mathrm{M})$ of D-CPP had no effect on the amplitudes of these fast cur- rents (Fig. $2 \mathrm{H}, I)$ or on their paired-pulse ratio (ISI, $40 \mathrm{msec}$ ) (Fig. $2 H, I$ ). Thus, presynaptic effects of D-CPP did not play a role in our experiments.

We conclude that the increased fraction of failures in the presence of D-CPP is attributable to an increased incidence of receptor failures. Because an increase in failures can be detected with moderate block, it is likely that very few $(<5)$ NMDA-Rs open after glutamate release at central glutamatergic synapses. Furthermore, in the presence of drug receptor failures are frequent, and a sizable fraction of successes must be attributable to the activation of individual receptors. Because it is still possible reliably to separate failures and success, these experiments directly demonstrate that the opening of single synaptic NMDA-Rs can be reliably detected.

\section{Biophysical model}

Our results indicate that failures and successes can be clearly distinguished even in the case in which only a single NMDA-R opens. To test whether this finding is consistent with the properties of NMDA-Rs, our knowledge of the handling of $\mathrm{Ca}^{2+}$ in spines, and the nature of the $\mathrm{Ca}^{2+}$-sensitive dyes we use, we developed a realistic biophysical model of $\left[\mathrm{Ca}^{2+}\right]$ dynamics. Based on previous measurements of the volumes of dendritic spines, the properties of NMDA-Rs, the parameters describing $\mathrm{Ca}^{2+}$ handling in spines, and the shot noise characteristics of our measurements (Sabatini and Svoboda, 2000), we were able to simulate experiments without free parameters (Table 1) (see Materials and Methods).

We simulated a large number of trials and plotted their amplitude distributions. The amplitude distribution has two clearly separated peaks, corresponding to receptor failures and successes (Fig. 3). Because of the large $\mathrm{Ca}^{2+}$ permeability of the NMDA-R (Jahr and Stevens, 1993) most $\left[\mathrm{Ca}^{2+}\right]$ transients, even when produced by the opening of a single NMDA-R, on average, saturated the $\mathrm{Ca}^{2+}$ indicator, producing large fluorescence changes (Fig. $3)$. In our simulations, as in the experiments, trials with synaptic $\left[\mathrm{Ca}^{2+}\right]$ transients ("successes") were clearly differentiable from trials in which no $\left[\mathrm{Ca}^{2+}\right]$ transient was elicited ("failures") (Figs. $2 B, C, 3)$. As expected, as $n$ increased from 1 to 3 , the numbers of failures decreased, although they remained detectable. Similar results were obtained when the simulations incorporated variability in vesicle size and in the location of the release site within the synapse (Franks et al., 2002), although the number of failures decreased slightly (Fig. 3).

\section{Failure analysis assay to measure $n$}

Based on the observation of increased failures in subsaturating concentrations of D-CPP, we developed an assay to count the number of NMDA-Rs opening after synaptic transmission ("failure analysis"). This analysis assumes that the opening of single NMDA-Rs can be detected but is otherwise independent of the detailed biophysical properties of the NMDA-R. The basic idea underlying our assay is to increase the number of failures (to probability $f^{\prime}>f$ ) by adding D-CPP. As discussed above, this manipulation specifically enhances receptor failures. Keeping track of failure probabilities $f$ and $f^{\prime}$ by imaging $\left[\mathrm{Ca}^{2+}\right]$ transients, and of the fractional block of NMDA-Rs by measuring the wholecell current before and after application of drug ( $I$ and $\left.I^{\prime}\right)$, allows us to calculate the number of receptors opening after transmitter release, $n$, by solving the equation (see Materials and Methods for 


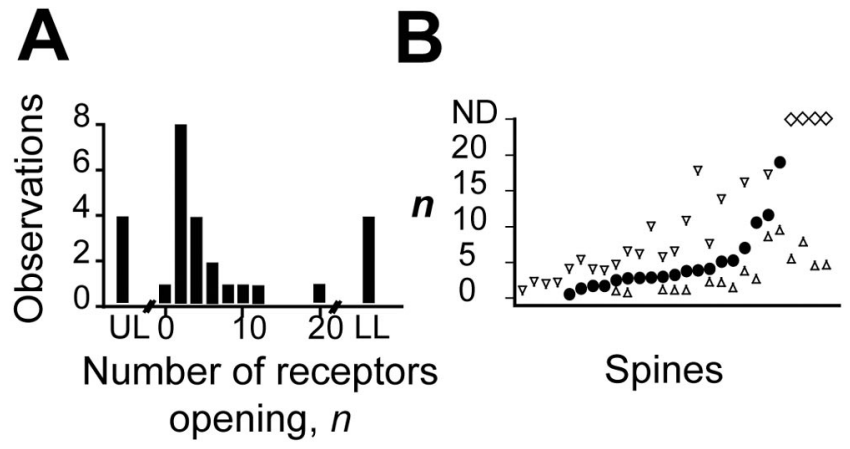

Figure 4. Results from the failure analysis assay. A, Distribution of calculated values of $n$. Most synapses had small values of $n$. Synapses in which only an upper or lower limit could be computed are assigned to bins labeled UL and LL, respectively. $B$, Values of $n$ ordered by magnitude. The solid circles represent the mean value of $n$ obtained for each synapse. Only spines where at least an upper or lower limit could be computed are shown. Spines where a lower limit, but not the mean $n$, could be determined are indicated with diamonds. Lower (upright triangles) and upper (inverted triangles) limits, when calculable, are indicated.

a derivation of this formula and additional discussion of the assumptions underlying its derivation):

$$
\frac{1-f}{1-e^{-n}}-\frac{1-f^{\prime}}{1-e^{-n I^{\prime} / I}}=0 .
$$

Here, $n$ is the number of receptors that open at some time after release.

The failure analysis assay (Eq. 16) produces a quantitative estimate of the number of NMDA-Rs opening on spines of hippocampal CA1 pyramidal neurons. We measured failure probabilities before and after application of D-CPP (in the example shown, $f=0.71, f^{\prime}=0.83$ ) (Fig. 2, compare $B, C$ ). Because we measured failure probabilities before and after drug and the average fractional block detected with the somatic patch electrode (Fig. 2E), we can estimate the number of channels opening during low-frequency synaptic transmission (Eq. 16). For the synapse of Figure 2, $B, C$, and $E$, we derived $n=0.53$ (upper limit, 4.0 ). This means that, on average, $\sim 0.5$ receptors were bound by glutamate and opened some time during the response; therefore, in this example, even in the absence of drug, receptor failures accounted for a considerable fraction of failures. Similar measurements at a population of synapses revealed that typically only a few NMDA-Rs open during low-frequency synaptic transmission (median, 3.2; range, $0.5-19 ; N=19$ ) (Fig. $4 A, B$ ). At eight additional synapses, only upper limits $(N=4)$ or lower limits $(N=4)$ could be computed; these were likely to be synapses with relatively small or large values of $n$, respectively (Fig. $4 B$ ). Indistinguishable results were obtained in the presence of $1 \mu \mathrm{M}$ thapsigargin (median, $n=2.9 ; N=5$ ), which blocks the sarcoendoplasmic reticulum calcium-ATPase pump with high affinity $\left(K_{\mathrm{d}}\right.$, $\sim 10^{-9} \mathrm{M}$ ) (Sagara and Inesi, 1991), depleting calcium stores (Thastrup et al., 1990) (see Materials and Methods).

Using the failure analysis assay, we could obtain values of $n$ for synapses with $n<10$. At some synapses $(N=7)$, the failure rate in D-CPP was statistically indistinguishable from baseline conditions, despite a substantial block of the whole-cell current. We consider three possibilities to account for these synapses:

(1) It could be that in some experiments drift in failure probability, $f$, could contribute to errors in our estimation in $n$. We addressed the issue of nonstationarity by measuring failure rates for two epochs of time identical to those used in the failure analysis assay, but without drug application ( $N=15$ synapses). Over-

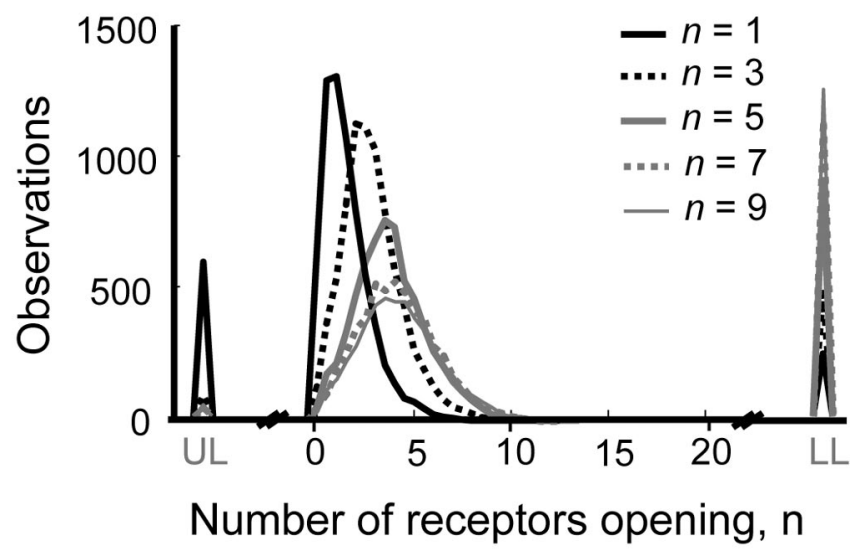

Figure 5. Simulation of the failure analysis assay. To generate the distributions, $P_{r}$ was varied from 0.1 and 0.9 , and partial block $\left(I^{\prime} / I\right)$ from 0.4 and 0.7 . The number of trials per observation was in the range 60-100, as in our experiments. Note the presence of synapses for which only upper limits (UL) or lower limits (LL) can be obtained, consistent with what was observed experimentally (compare with Fig. $4 A$ ). These cases are attributable to sampling errors in estimating $f$. As $n$ increases, the failure analysis becomes relatively insensitive to the value of $n$, and $\mathrm{LL}$ cases increase.

all, there was no significant change in failure rates (mean overall failure rates were $0.54 \pm 0.04$ and $0.57 \pm 0.04$ for epochs 1 and 2, respectively; $p>0.3$ ) (Fig. $2 G$ ). This was in contrast to the mean change across epochs in experiments in which D-CPP was added [mean overall failure rates for 45 synapses (including those in which no upper or lower limit could be computed) were $0.44 \pm$ 0.03 before D-CPP and $0.58 \pm 0.03$ after D-CPP; $p \ll 0.001$ ) (Fig. $2 F$ ). Thus, in the absence of added NMDA-R blocker, there was no change in the failure rates across observed synapses, ruling out a systematic bias in our measurements. To obtain an estimate of the error attributable to fluctuations in $f$, we performed measurements in consecutive epochs consisting of 80 trials (equivalent to the mean number of trials used in the failure analysis) in 15 synapses, obtaining the CV of these values. Although the CV was higher $(\sim 45 \%)$ than expected for a random process with fixed failure rate (suggesting that failure rates fluctuated slightly), this error does not significantly affect our measurement of $n$ (see Materials and Methods).

(2) Cases in which the failure rate does not change significantly could be attributable to the stochastic error in estimating failure probabilities associated with finite samples. To test this, we performed Monte Carlo simulations of the failure analysis assay. As expected, these simulations revealed that our estimate of $n$ becomes progressively more unreliable with larger numbers of receptors opening (Fig. 5). Surprisingly, even with moderate values of $n(n>5)$, stochastic errors in estimating $f$ and $f^{\prime}$ can, in some instances, make estimates of $n$ impossible [corresponding to counts in the LL (lower limit) bin] (Fig. 5). Furthermore, the number of synapses at which failure rates did not change significantly, and hence with apparently large $n$, is in a range consistent with this error and receptor numbers in the range 4-10. In other words, the failure analysis assay clearly demonstrates that for most synapses $n<5$, but the assay does not provide information regarding the existence of synapses with $n>5$.

(3) These cases could belong to a relatively small population at which large numbers of receptors open, and, therefore, the failure rate does not change significantly. Such synapses are difficult to analyze using the failure analysis assay, and $n$, therefore, cannot be determined reliably. We test this possibility in our amplitude analysis (see below). 


\section{Amplitude analysis assay to measure $n$}

Because of the uncertainties of the failure analysis assays in estimating $n$ for synapses with $n>5$, we developed a second assay ("amplitude analysis") for estimating the number of NMDA-Rs opening during synaptic transmission. This assay allows us to search for synapses with large $n$ and thereby to distinguish between possibilities 2 and 3 above. In the amplitude analysis assay, estimates of the total $\mathrm{Ca}^{2+}$ influx into spines are used to derive the number of receptors opening. Measurements were performed under conditions in which $\Delta G / R$ is a linear reporter of $\left[\mathrm{Ca}^{2+}\right]$ transients and, hence, proportional to $n$, such that $\Delta G /$ $r=c n / V_{\text {sp }}$. Here, $V_{\text {sp }}$ is the measured spine volume, and $c$ is the change in fluorescence produced by the opening of a single channel in a unit volume. Linearity was enforced by using the lowaffinity indicator Fluo-4FF $\left(K_{\mathrm{d}}, 9.7 \mu \mathrm{M}\right)$, following the same protocol as described above for the failure analysis with Fluo-4. Our biophysical model of $\left[\mathrm{Ca}^{2+}\right]$ dynamics supported the assertion of linearity, because even $\left[\mathrm{Ca}^{2+}\right]$ transients produced by relatively large numbers of NMDA-Rs (e.g., 5) failed to saturate the dye (data not shown). Lack of dye saturation was also borne out experimentally, because $\left[\mathrm{Ca}^{2+}\right]$ signals generated by the opening of VSCCs when the neuron was rapidly depolarized to $+20 \mathrm{mV}$ from rest produced $\Delta G / R$ values $(>3.8)$, greatly in excess of those we obtained at synapses (overall mean across 28 experiments, $0.87 \pm 0.08$; largest trial for any synapse, $\Delta G / R=3.3$ ).

Even under conditions of linearity, in some spines $(N=6)$ successes were still clearly differentiable from failures, although, as expected, a greater range of response amplitudes was observed (Fig. 6A-D). For these selected spines, we could determine $\Delta G$ / $R, V_{\text {sp }}$ and $n$ (using failure analysis) simultaneously and thereby derive $c$. The amplitude assay is, therefore, dependent on the failure analysis assay to derive $c$. However, because $c$ is a constant for all spines, we could then use measurements of $\Delta G / R$ and $V_{\mathrm{sp}}$ to derive $n$ for other spines. The values for $n$ obtained using the amplitude analysis assay were essentially consistent with those found with the failure analysis (Fig. 7A). Importantly, in these measurements there was no evidence of large values of $n$. These measurements, and the analysis of the failure analysis assay summarized in Figure 5, indicate that the large apparent values of $n$ for some synapses (i.e., the bin labeled LL in Fig. 4A) were attributable to the error in accurate estimates of the failure rates. Based on both assays, we conclude that for most synapses $n$ is in the range of $1-10$.

Studies of EPSC amplitude have suggested that distant synapses are more potent than those closer to the soma (Andersen et al., 1980), and a systematic variation in the number of receptors per synapse has been suggested (Andrasfalvy and Magee, 2001). To address this possibility for NMDA-Rs, we plotted our estimates of $n$ against the linear distance from the soma (Fig. $7 B$ ). However, no significant correlation between $n$ and distance from the soma was found (Spearman's $r=-0.32 ; p>0.05 ; N=21$ ). The absence of a correlation between $n$ and the distance of a synapse from the soma is consistent with a recent study that found that AMPA-Rs, but not NMDA-Rs, vary in density depending on position in the dendritic tree (Andrasfalvy and Magee, 2001). $n$ was also not correlated with release probability $(r=0.18$; $p>0.05$ ) (Fig. 7C), which is thought to correlate with synaptic size (Murthy et al., 2001). In addition, previous studies have shown that the number of channels on spines correlates with spine volume for VSCCs (Sabatini and Svoboda, 2000) and AMPA-Rs (Nusser et al., 1998; Matsuzaki et al., 2001). Total NMDA-R number, in contrast, as determined by immunoelectron microscopy, is only weakly correlated with PSD area (Racca et al., 2000). To test whether the num-
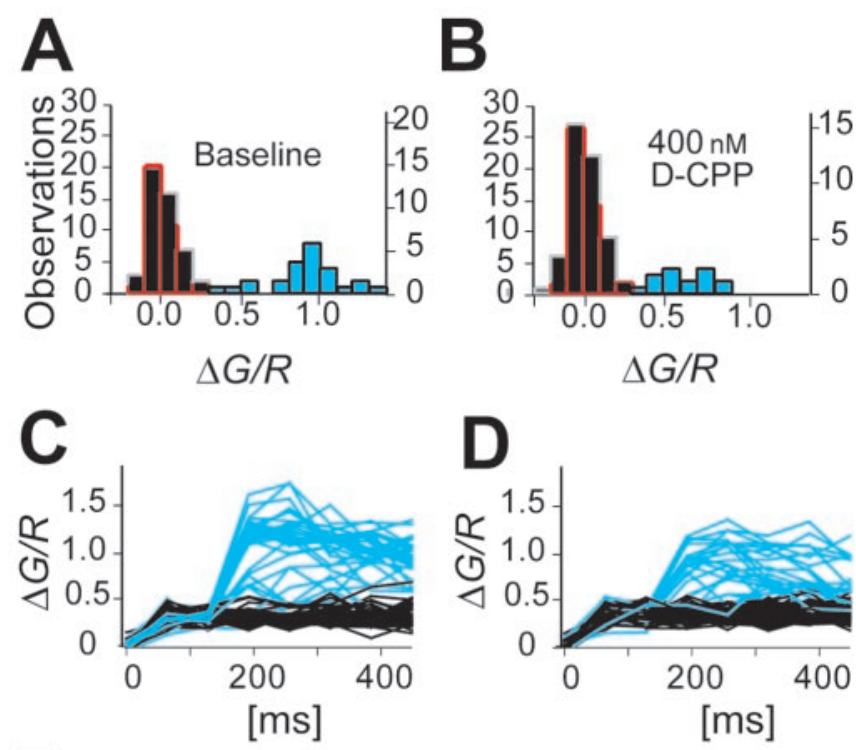

EE

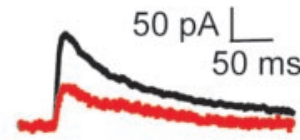

Figure 6. Amplitude analysis assay to determine the number of NMDA-Rs opening at single synapses. $A, B$, Frequency distributions of NMDA-R-mediated calcium signals imaged using the low-affinity indicator Fluo-4FF before $(A)$ and in the presence of $(B) D$-CPP. Under conditions of partial blockade, failures (black bars) increased at the expense of successes (blue bars). Open histograms (red; right axis) indicate the distribution of $\Delta G / R$ in trials when no stimulus was delivered. $C, D,\left[\mathrm{Ca}^{2+}\right]$ transients corresponding to $A$ and $B$. Note the wide range of response amplitudes and the overall decrease in amplitude in the presence of $400 \mathrm{~nm} D-C P P(D) . E$, NMDA-R-mediated EPSCs before (black) and after (red) the addition of $400 \mathrm{~nm} \mathrm{D-CPP.}$

ber of NMDA-Rs opened correlated with synaptic size, we measured spine volume, which is proportional to PSD area (Harris and Stevens, 1989). The mean spine volume for the population $(0.081 \pm$ $0.04 \mathrm{fL}$; mean $\pm \mathrm{SD}$ ) was comparable with the reported value based on serial section EM (0.062 $\pm 0.08 \mathrm{fL})$ (Harris and Stevens, 1989). $n$ was only weakly correlated with spine volume (Fig. 7D) (Spearman's rank coefficient $r=0.49 ; p<0.05$ ). In contrast, the mean $\Delta G / R$ across successes, which is proportional to the mean change in $\left[\mathrm{Ca}^{2+}\right]$, was highly correlated with the inverse of the spine volume $(r=0.65 ; p=0.001)$ (Fig. $7 E)$. This suggests that the number of NMDA-Rs opening does not scale with spine volume and that smaller spines have larger NMDA-R-mediated $\left[\mathrm{Ca}^{2+}\right]$ changes than bigger spines.

\section{Estimating the number of AMPA-Rs opening}

Using the number of NMDA-Rs opened during synaptic transmission, we can estimate the number of AMPA-Rs opening. The conductance through NMDA-Rs at the peak of the EPSC is given by $n \cdot \gamma_{\mathrm{N}} \cdot N_{s} \cdot p_{o}$, where $\gamma_{\mathrm{N}}$ is single channel conductance for the NMDA-R and $N_{s}$ is the number of active synapses. Analogously, the conductance through AMPA-Rs in the same cell is given by $n_{\mathrm{A}}$ - $\gamma_{\mathrm{A}} \cdot N_{s} \cdot p_{o A}$, where $p_{o A}$ is the open probability of the AMPA-R. Thus $n_{\mathrm{A}}$, the number of AMPA-Rs opening, on average, is given by AMPA/NMDA $\cdot n \cdot \gamma_{\mathrm{N}} / \gamma_{\mathrm{A}} \cdot p_{o} / p_{o A}$, where AMPA/NMDA is the ratio of the peak AMPA-R- and NMDA-R-mediated components of the EPSC. AMPA-R/NMDA-R ratios were obtained by measuring the amplitudes of EPSCs in the presence and in the absence 
A

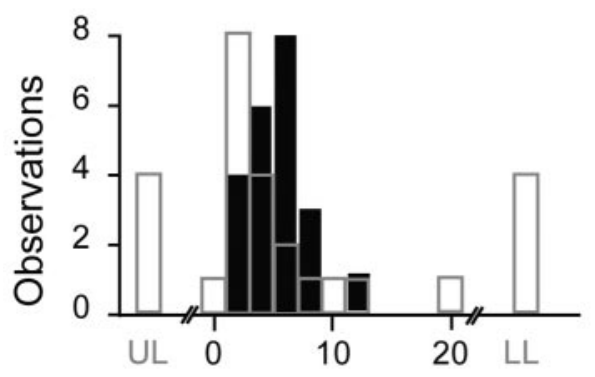

Number of receptors opening, $n$

B

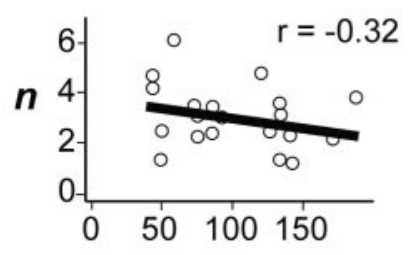

Distance from soma $[\mu \mathrm{m}]$
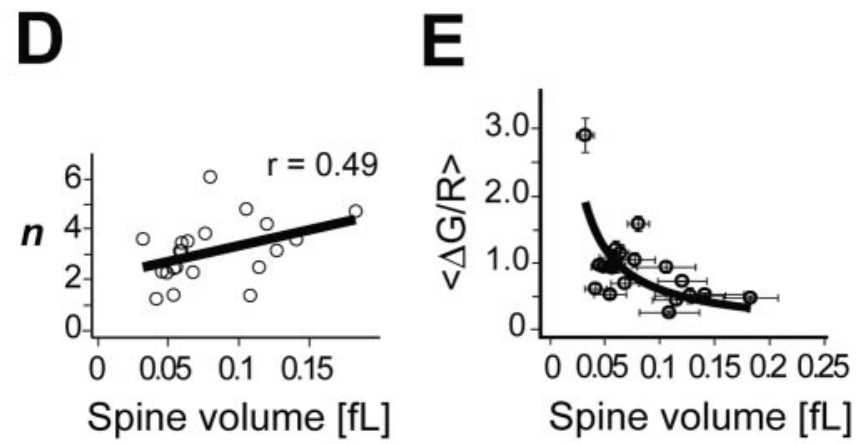

Figure 7. Results of the amplitude analysis assay. $A$, Distribution of calculated values of $n$ (solid black bars). Most synapses had small values of $n$, and very large values were not observed. The values obtained using the failure analysis (Fig. $4 A$ ) are replotted for comparison (gray bars). $B, C$, Values of $n$ plotted against the linear distance of the synapse from the soma $(B)$ and release probability (C). $D$, Values of $n$ plotted against spine volume. $E$, The mean $\Delta G / R(<\Delta G / R>)$ plotted against spine volume. Note the decay of $<\Delta G / R>$ with (volume) ${ }^{-1}$. Error bars represent SEM.

of $10 \mu \mathrm{M}$ D-CPP (Fig. $8 A, B)$. Using this value $(0.61 \pm 0.06 ; N=$ $9)$, the mean calculated $n$ (3.1) and published values for $\gamma_{\mathrm{N}}$ (40-50 pS) (Gibb and Colquhoun, 1992), $\gamma_{\mathrm{A}}(8 \mathrm{pS})$ (Jonas and Sakmann, 1992), $p_{o}(0.3)$ (Jahr, 1992), and $p_{o A}(0.6)$ (Spruston et al., 1995), we derived $n_{\mathrm{A}}=5.9$. This value represents the mean $n_{\mathrm{A}}$ across all NMDA-R-containing synapses, including silent synapses that lack AMPA-Rs. The number of functionally silent Schaffer collateral-CA1 synapses at this age is unknown. However, taking the value from immunoelectron microscropy [28\% for commissural-associational synapses in CA3 at P17 (Nusser et al., 1998)] as an upper limit, this means that the mean number of AMPA-Rs opening in nonsilent synapses is $<10$.
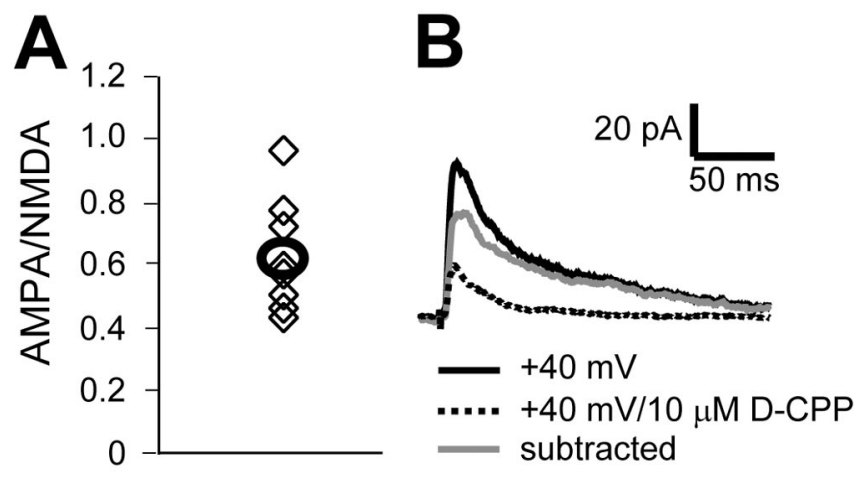

Figure 8. Measuring AMPA-R/NMDA-R ratios. A, AMPA-R/NMDA-R ratios in postnatal day $16-19$ rats. Open triangles represent the means for each experiment, and the overall mean is indicated by the black circle. These values agree with previous reports of the same quantity (Hsia et al., 1998). B, Method for obtaining AMPA-R/NMDA-R ratios. Baseline trials (black solid trace) were taken at $40 \mathrm{mV}$ above the reversal potential. Then, $10 \mu \mathrm{m}$ D-CPP was added, and additional trials were obtained (AMPA-R component; dotted line). The trace in the presence of $D-C P P$ was subtracted from that in its absence to obtain the NMDA-R component (gray trace). The amplitudes of the AMPA-R and NMDA-R components were computed for the AMPA-R/ NMDA-R ratio, which in the present example was 0.46 . The response remaining after $D-C P P$ was eliminated by $10 \mu \mathrm{m}$ NBQX.

\section{Discussion}

On glutamate release, NMDA-Rs bind glutamate and rapidly transition between open and closed states with an open probability of $p_{o} \sim 0.3$ until glutamate unbinds (Jahr, 1992; Dzubay and Jahr, 1996; Wyllie et al., 1998). We find that synaptic transmission at low frequencies leads to a remarkably small number of NMDA-Rs opening at hippocampal synapses (median $n, \sim 3$ ). Most NMDA-Rs that bind glutamate also open. Thus, $n$ is approximately equal to the number of receptors bound by glutamate, and during the peak of the postsynaptic current, $p_{o} \cdot n \sim 1$ receptors are open, on average. This corresponds to a current on the order of $\sim 2 \mathrm{pA}$ ( at $+40 \mathrm{mV}$ ), below the detection threshold under typical experimental conditions. Under conditions of $\mathrm{Mg}^{2+}$ block, the number of open receptors and corresponding currents will even be smaller (Jahr and Stevens, 1990). Thus, for many synapses, quantal NMDA-R currents generated in the dendrite are expected to be electrophysiologically unmeasurable at the soma. Other estimates of the number of receptors opening at the same synapses are based on comparing single-channel conductances with the size of miniature currents and produced larger estimates, $p_{o} \cdot n \leq 8$ or $n \leq 24$ (Bekkers and Stevens, 1989; Spruston et al., 1995). The discrepancy is likely attributable to the fact that in these studies a subset of extremely large miniature currents were selected to compute the number of receptors. In certain unusual, electrically compact systems that allow highquality electrical measurements, such as immature cerebellar granule cells (Silver et al., 1992) and immature, unusually small, cultured hippocampal neurons (Robinson et al., 1991), it has been possible directly to resolve synaptically activated singlechannel currents. These studies have provided conclusions in line with our data.

The small number of receptors opening, independent of synapse size, has several implications. In the absence of receptor saturation (Mainen et al., 1999a; Umemiya et al., 1999; McAllister and Stevens, 2000) (see below), stochastic interactions between populations of neurotransmitter molecules and receptors produce noise with a $\mathrm{CV} \sim 1 / \sqrt{ } n$. The small size of $n$ (Figs. $4 A$, $7 A$ ) indicates that receptor fluctuations contribute significantly to noise in synaptic transmission. At some synapses, receptor 
fluctuations, rather than fluctuations produced by the glutamate release process (Franks et al., 2002), might constitute the dominant noise source.

We have shown that even with a substantial number of receptor failures (in the presence of antagonist) (Fig. 2C), successes and failures often were still clearly distinguishable. Under these conditions, a fraction of responses is attributable to the opening of individual receptors. We conclude that the opening of single NMDA-Rs can be observed using $\left[\mathrm{Ca}^{2+}\right]$ imaging in spines ( $\mathrm{Sa}-$ batini and Svoboda, 2000). This conclusion is supported by realistic biophysical simulations without free parameters (Fig. 3). Thus, $\left[\mathrm{Ca}^{2+}\right]$ imaging opens the way for biophysical studies of synaptic receptors in situ.

Although $\left[\mathrm{Ca}^{2+}\right]$ transients are produced by the opening of a small number of receptors, the broad distribution of open times reported for NMDA-Rs is expected to obliterate quantal peaks of $\Delta G / R$ amplitude corresponding to different values of $n$ (Gibb and Colquhoun, 1992). This prediction is supported by the present data, in which even under nonsaturating dye conditions, quantal peaks are not evident (Fig. 6A,B). One surprising observation is that the variance in response amplitude with the low-affinity dye is often lower than might be expected from such a small number of receptors opening, coupled with variability in vesicle number (Oertner et al., 2002) and size (Harris and Sultan, 1995) (data not shown). One possible mechanism explaining this behavior is local receptor saturation: receptor saturation in a restricted patch of postsynaptic membrane immediately apposed to the release site of glutamate.

Our measurements of $n$ allow us to refine previous estimates of NMDA-R occupancy (30-60\%), the fraction of NMDA-Rs bound to glutamate (Mainen et al., 1999a; Umemiya et al., 1999; McAllister and Stevens, 2000). Because the majority of NMDA-Rs bound by glutamate are sensitive to the usedependent open-channel NMDA-R blocker MK-801 (Jahr, 1992; Dzubay and Jahr, 1996), the number of receptors opened is approximately equal to the number of receptors bound by glutamate. To calculate occupancy, we need an estimate of the number of NMDA-Rs on synaptic membranes, which can be derived from immunoEM studies (Petralia et al., 1999; Racca et al., 2000). Taking the number of gold particles counted per synapse as a lower bound on the number of receptor molecules at the synapse, this value (>8) (Racca et al., 2000), taken together with the values of $n$ described here, point to a receptor occupancy of $<40 \%$. Thus, the amount of glutamate released into the cleft and the dynamics of glutamate handling play important roles in determining the mean amplitude of the postsynaptic response, whereas the stochastic nature of receptor opening contributes to its variability.

The low occupancy we find for synaptic NMDA-Rs indicates that the amplitude and duration of the glutamate transient in the cleft must be smaller than previously thought (Clements et al., 1992). Changes in the amplitude and time course of the glutamate transient in the cleft would change NMDA-R occupancy and the postsynaptic response amplitude. The glutamate transient is shaped by a multitude of factors, including the dynamics of the glutamate release process, cleft geometry, buffering, and extrusion, all of which could be modulated during synaptic plasticity. One consequence is that the use of open-channel blockers, such as MK-801, cannot be readily interpreted as a measure of absolute or relative synaptic release probability (Hessler et al., 1993; Rosenmund et al., 1993). Low occupancy further implies that the dynamic range of synapses is large, with NMDA-R activation produced by bursts larger than that produced by single stimuli.
The estimated number of AMPA-Rs opening with a synaptic response is larger than the number of NMDA-Rs opening, but our methods did not permit us to characterize the distribution of values. However, the distribution of AMPA-R proteins at these synapses is strongly skewed to the right (Nusser et al., 1998), so that there is a small population of synapses, mostly at large, mushroom-shaped spines, which contain very large numbers of AMPA-Rs (Matsuzaki et al., 2001). This, taken together with the present findings, suggests that at most synapses the number of AMPA-Rs opening is also small (probably $<10$ ).

The relatively invariant contribution of NMDA-Rs to the postsynaptic response across synaptic size is consistent with immunoelectron microscopic data (Takumi et al., 1999; Racca et al., 2000) obtained at these synapses. It is also in accordance with numerous studies that have found NMDA-Rs and AMPA-Rs to be independently regulated in hippocampal neurons (Rao and Craig, 1997; Lissin et al., 1998; Liao et al., 1999; but see Watt et al., 2000).

Finally, because different-sized spines experience different $\left[\mathrm{Ca}^{2+}\right]$, and because the amplitude of the $\left[\mathrm{Ca}^{2+}\right]$ transient is critical for determining the degree and the direction of changes in synaptic efficacy (Cummings et al., 1996; Yang et al., 1999), spines with different volumes could be differentially susceptible to different forms of synaptic plasticity.

\section{References}

Andersen P, Silfvenius H, Sundberg SH, Sveen O (1980) A comparison of distal and proximal dendritic synapses on CA1 pyramids of guinea-pig hippocampal slices in vitro. J Physiol (Lond) 307:273-299.

Andrasfalvy BK, Magee JC (2001) Distance-dependent increase in AMPA receptor number in the dendrites of adult hippocampal CA1 pyramidal neurons. J Neurosci 21:9151-9159.

Bading H, Ginty DD, Greenberg ME (1993) Regulation of gene expression in hippocampal neurons by distinct calcium signaling pathways. Science 260:181-186.

Bekkers JM, Stevens CF (1989) NMDA and non-NMDA receptors are colocalized at individual excitatory synapses in cultured rat hippocampus. Nature 341:230-233.

Casado M, Isope P, Ascher P (2002) Involvement of presynaptic N-methylD-aspartate receptors in cerebellar long-term depression. Neuron 33:123-130.

Clements JD, Lester RA, Tong G, Jahr CE, Westbrook GL (1992) The time course of glutamate in the synaptic cleft. Science 258:1498-1501.

Cummings JA, Mulkey RM, Nicoll RA, Malenka RC (1996) $\mathrm{Ca}^{2+}$ signaling requirements for long-term depression in the hippocampus. Neuron $16: 825-833$.

Denk W, Svoboda K (1997) Photon upmanship: why multiphoton imaging is more than a gimmick. Neuron 18:351-357.

Denk W, Strickler JH, Webb WW (1990) Two-photon laser scanning microscopy. Science 248:73-76.

Dzubay JA, Jahr CE (1996) Kinetics of NMDA channel opening. J Neurosci 16:4129-4134

Franks KM, Bartol Jr TM, Sejnowski TJ (2002) A Monte Carlo model reveals independent signaling at central glutamatergic synapses. Biophys J 83:2333-2348.

Franks KM, Stevens CF, Sejnowski TJ (2003) Independent sources of quantal variability at single glutamatergic synapses. J Neurosci 23:3186-3195.

Garaschuk O, Yaari Y, Konnerth A (1997) Release and sequestration of calcium by ryanodine-sensitive stores in rat hippocampal neurones. J Physiol (Lond) 502:13-30.

Gibb AJ, Colquhoun D (1992) Activation of N-methyl-D-aspartate receptors by L-glutamate in cells dissociated from adult rat hippocampus. J Physiol (Lond) 456:143-179.

Harris KM, Stevens JK (1989) Dendritic spines of CAl pyramidal cells in the rat hippocampus: serial electron microscopy with reference to their biophysical characteristics. J Neurosci 9:2982-2997.

Harris KM, Sultan P (1995) Variation in the number, location and size of synaptic vesicles provides an anatomical basis for the nonuniform probability of release at hippocampal CA1 synapses. Neuropharmacology 34:1387-1395. 
Harris KM, Jensen FE, Tsao B (1992) Three-dimensional structure of dendritic spines and synapses in rat hippocampus (CA1) at postnatal day 15 and adult ages: implications for the maturation of synaptic physiology and long-term potentiation. J Neurosci 12:2685-2705.

Hessler NA, Shirke AM, Malinow R (1993) The probability of transmitter release at a mammalian central synapse. Nature 366:569-572.

Hsia AY, Malenka RC, Nicoll RA (1998) Development of excitatory circuitry in the hippocampus. J Neurophysiol 79:2013-2024.

Jahr CE (1992) High probability opening of NMDA receptor channels by L-glutamate. Science 255:470-472.

Jahr CE, Stevens CF (1990) Voltage dependence of NMDA-activated macroscopic conductances predicted by single-channel kinetics. J Neurosci 10:3178-3182.

Jahr CE, Stevens CF (1993) Calcium permeability of the $N$-methyl-Daspartate receptor channel in hippocampal neurons in culture. Proc Natl Acad Sci USA 90:11573-11577.

Jonas P, Sakmann B (1992) Glutamate receptor channels in isolated patches from CA1 and CA3 pyramidal cells of rat hippocampal slices. J Physiol (Lond) 455:143-171.

Kleinschmidt A, Bear MF, Singer W (1987) Blockade of NMDA receptors disrupts experience-dependent plasticity of kitten striate cortex. Science 238:355-358.

Kovalchuk Y, Eilers J, Lisman J, Konnerth A (2000) NMDA receptormediated subthreshold $\mathrm{Ca}(2+)$ signals in spines of hippocampal neurons. J Neurosci 20:1791-1799.

Lester RA, Clements JD, Westbrook GL, Jahr CE (1990) Channel kinetics determine the time course of NMDA receptor-mediated synaptic currents. Nature 346:565-567.

Liao D, Zhang X, O’Brien R, Ehlers MD, Huganir RL (1999) Regulation of morphological postsynaptic silent synapses in developing hippocampal neurons. Nat Neurosci 2:37-43.

Lissin DV, Gomperts SN, Carroll RC, Christine CW, Kalman D, Kitamura M, Hardy S, Nicoll RA, Malenka RC, von Zastrow M (1998) Activity differentially regulates the surface expression of synaptic AMPA and NMDA glutamate receptors. Proc Natl Acad Sci USA 95:7097-7102.

Liu G, Choi S, Tsien RW (1999) Variability of neurotransmitter concentration and nonsaturation of postsynaptic AMPA receptors at synapses in hippocampal cultures and slices. Neuron 22:395-409.

Magee JC, Cook EP (2000) Somatic EPSP amplitude is independent of synapse location in hippocampal pyramidal neurons. Nat Neurosci 3:895-903.

Magee JC, Johnston D (1995) Characterization of single voltage-gated $\mathrm{Na}^{+}$ and $\mathrm{Ca}^{2+}$ channels in apical dendrites of rat CA1 pyramidal neurons. J Physiol (Lond) 487:67-90.

Mainen ZF, Malinow R, Svoboda K (1999a) Synaptic calcium transients in single spines indicate that NMDA receptors are not saturated. Nature 399:151-155.

Mainen ZF, Maletic-Savatic M, Shi SH, Hayashi Y, Malinow R, Svoboda K (1999b) Two-photon imaging in living brain slices. Methods 18:231-239.

Matsuzaki M, Ellis-Davies GC, Nemoto T, Miyashita Y, Iino M, Kasai H (2001) Dendritic spine geometry is critical for AMPA receptor expression in hippocampal CA1 pyramidal neurons. Nat Neurosci 4:1086-1092.

McAllister AK, Stevens CF (2000) Nonsaturation of AMPA and NMDA receptors at hippocampal synapses. Proc Natl Acad Sci USA 97:6173-6178.

Murthy VN, Sejnowski TJ, Stevens CF (1997) Heterogeneous release properties of visualized individual hippocampal synapses. Neuron 18:599-612.

Murthy VN, Schikorski T, Stevens CF, Zhu Y (2001) Inactivity produces increases in neurotransmitter release and synapse size. Neuron 32:673-682.

Neher E, Augustine GJ (1992) Calcium gradients and buffers in bovine chromaffin cells. J Physiol (Lond) 450:273-301.

Nimchinsky EA, Sabatini BL, Svoboda K (2002) Structure and function of dendritic spines. Annu Rev Physiol 64:313-353.

Nusser Z, Lujan R, Laube G, Roberts JD, Molnar E, Somogyi P (1998) Cell type and pathway dependence of synaptic AMPA receptor number and variability in the hippocampus. Neuron 21:545-559.

Oertner TG, Sabatini BS, Nimchinsky EA, Svoboda K (2002) Facilitation at single synapses probed with optical quantal analysis. Nat Neurosci 5:657-664.

Petralia RS, Esteban JA, Wang YX, Partridge JG, Zhao HM, Wenthold RJ, Malinow R (1999) Selective acquisition of AMPA receptors over postnatal development suggests a molecular basis for silent synapses. Nat Neurosci 2:31-36.

Pologruto T, Sabatini BL, Svoboda K (2003) Flexible software for operating laser-scanning microscopes. BioMedical Engineering OnLine 2.

Racca C, Stephenson FA, Streit P, Roberts JD, Somogyi P (2000) NMDA receptor content of synapses in stratum radiatum of the hippocampal CA1 area. J Neurosci 20:2512-2522.

Rao A, Craig AM (1997) Activity regulates the synaptic localization of the NMDA receptor in hippocampal neurons. Neuron 19:801-812.

Robinson HP, Sahara Y, Kawai N (1991) Nonstationary fluctuation analysis and direct resolution of single channel currents at postsynaptic sites. Biophys J 59:295-304.

Rosenmund C, Clements JD, Westbrook GL (1993) Nonuniform probability of glutamate release at a hippocampal synapse. Science 262:754-757.

Sabatini BL, Svoboda K (2000) Analysis of calcium channels in single spines using optical fluctuation analysis. Nature 408:589-593

Sabatini BS, Oertner TG, Svoboda K (2002) The life-cycle of $\mathrm{Ca}^{2+}$ ions in spines. Neuron 33:439-452.

Sagara Y, Inesi G (1991) Inhibition of the sarcoplasmic reticulum $\mathrm{Ca}^{2+}$ transport ATPase by thapsigargin at subnanomolar concentrations. J Biol Chem 266:13503-13506.

Schikorski T, Stevens CF (1997) Quantitative ultrastructural analysis of hippocampal excitatory synapses. J Neurosci 17:5858-5867.

Schneggenburger R, Zhou Z, Konnerth A, Neher E (1993) Fractional contribution of calcium to the cation current through glutamate receptor channels. Neuron 11:133-143.

Silver RA, Farrant M (1999) Neurotransmitter-gated ion channels in dendrites. In: Dendrites (Stuart G, Spruston N, Hausser M, eds), pp 114-130. Oxford: Oxford UP.

Silver RA, Traynelis SF, Cull-Candy SG (1992) Rapid-time-course miniature and evoked excitatory currents at cerebellar synapses in situ. Nature 355:163-166.

Sjostrom PJ, Turrigiano GG, Nelson SB (2003) Neocortical LTD via coincident activation of presynaptic NMDA and cannabinoid receptors. Neuron 39:641-654.

Spruston N, Jonas P, Sakmann B (1995) Dendritic glutamate receptor channels in rat hippocampal CA3 and CA1 pyramidal neurons. J Physiol (Lond) 482:325-352.

Takumi Y, Ramirez-Leon V, Laake P, Rinvik E, Ottersen OP (1999) Different modes of expression of AMPA and NMDA receptors in hippocampal synapses. Nat Neurosci 2:618-624.

Thastrup O, Cullen PJ, Drobak BK, Hanley MR, Dawson AP (1990) Thapsigargin, a tumor promoter, discharges intracellular $\mathrm{Ca}^{2+}$ stores by specific inhibition of the endoplasmic reticulum $\mathrm{Ca}^{2+}$-ATPase. Proc Natl Acad Sci USA 87:2466-2470.

Umemiya M, Senda M, Murphy TH (1999) Behaviour of NMDA and AMPA receptor-mediated miniature EPSCs at rat cortical neuron synapses identified by calcium imaging. J Physiol (Lond) 521:113-122.

Wadiche JI, Jahr CE (2001) Multivesicular release at climbing fiberPurkinje cell synapses. Neuron 32:301-313.

Watt AJ, van Rossum MCW, MacLeod KM, Nelson SB, Turrigiano GG (2000) Activity coregulates quantal AMPA and NMDA currents at neocortical synapses. Neuron 26:659-670.

Wyllie DJ, Behe P, Colquhoun D (1998) Single-channel activations and concentration jumps: comparison of recombinant NR1a/NR2A and NR1a/NR2D NMDA receptors. J Physiol (Lond) 510:1-18.

Yang SN, Tang YG, Zucker RS (1999) Selective induction of LTP and LTD by postsynaptic $\left[\mathrm{Ca}^{2+}\right]_{\mathrm{i}}$ elevation. J Neurophysiol 81:781-787.

Yasuda R, Nimchinsky EA, Scheuss V, Pologruto TA, Oertner TG, Sabatini BL, Svoboda K (2004) Imaging calcium concentration dynamics in small neuronal compartments. Sci STKE 2004:pl5

Yuste R, Denk W (1995) Dendritic spines as basic functional units of neuronal integration. Nature 375:682-684. 